\section{Small bowel transplantation for diffuse intestinal angiomatosis}

Sir,

Intestinal angiomatosis is a very rare phenomenon producing lower gastrointestinal bleeding. Its most frequent causes are diverticula, congenital arteriovenous malformation, acquired angiodysplasia, ischemia, inflammation, ulceration, benign or malignant tumours and iatrogenic injury.

In this paper, the case of a 48-year-old white man is reported. The patient required 14 months blood transfusions due to massive lower intestinal bleeding for diffuse intestinal angiomatosis from Treitz to ileum, with $2 \mathrm{~mm}-2 \mathrm{~cm}$-sized lesions. Initially, he complained of pain in the epigastric region and left shoulder. After 2 months an episode of melena with hypovolemic shock arose. Subsequently, he underwent an EGDS and a colonoscopy, both of which were negative for lesions. Six months later, a new episode of melena occurred and a repeated EGDS showed the presence of few gastric haemangiomas, which were removed through endoscopic laser coagulation. After 1 month the patient underwent an enteroscopy and an angiogram revealing the presence of jejunal and ileal angiomatosis. Three months later, after a new episode of bleeding, he underwent an exploratory laparotomy in a tertiary care centre: an ileal resection plus an intraoperative enteroscopy were performed, and the diagnosis of diffuse jejunal and ileal angiomatosis was confirmed. An MRI did not show cerebral angiomatosis. Owing to continuous lower GI bleeding requiring weekly blood transfusions, the patient was referred to our transplant centre. Thanks to the sudden availability of a donor, on August 17th, 2001 an enterectomy was performed followed by an isolated orthotopic small bowel transplant, with total ischemia time of $5 \mathrm{~h}$ and $25 \mathrm{~min}$. To date, this is the first report of a small bowel transplant for diffuse adult intestinal angiomatosis in the international English literature [1-3].

The patient recovered well and was able to be fed after 1 week. He was weaned off from parenteral nutrition and finally discharged after 14 days.

The immunosuppressive regimen was based on induction with Daclizumab (Zenapax ${ }^{\circledR}$ ) followed by a standard regimen of Tacrolimus (Prograf ${ }^{\circledR}$ ) and a rapid tapering of steroids.
Sirolimus (Rapamune ${ }^{\circledR}$ ) was added for renal failure for a limited period of time.

The following complications occurred: a sepsis due to central line infection, an enterocutaneous fistula post-ileostomy take-down (treated by $15 \mathrm{~cm}$ ileal resection) and a suspected Pseudomonas aeruginosa focus treated by right wedge pulmonary resection.

Following a left septic necrosis of femoral head due to $P$. aeruginosa, the patient is actually waiting for orthopaedic intervention. After 44 months he is in good condition showing good graft functionality.

\section{Conflict of interest statement}

None declared.

\section{References}

[1] Ehlert CP. Diffuse angiomatosis of the stomach, small intestine and colon. Chirurg 1964;35:372-4.

[2] Bernheim M, Gilly R, Germain D, Fournier P. Diffuse intestinal angiomatosis in the 7-year old child; diagnostic \& therapeutic problems. Pediatrie 1958;13:631-7.

[3] Delavierre P, Guerre J, Letac B. Diffuse angiomatosis of the small intestine. Semin Hopkins 1971;47:1187-8.

A. Lauro*

A. Dazzi

A.D. Pinna

Liver and Multiorgan Transplant Unit - Pad 25

University of Bologna, Policlinico Sant'Orsola-Malpighi Hospital, via Massarenti, 9, 40138 Bologna, Italy

F. di Benedetto

M. Masetti

N. Cautero

Liver and Multivisceral Transplant Center, University of Modena, Policlinico of Modena, Modena, Italy

20 May 2005

* Corresponding author. Tel.: +39051636 3721 fax: +390516363105 .

E-mail address: augustola@yahoo.com (A. Lauro) 